\title{
Transactions
}

Cite this: Dalton Trans., 2012, 41, 2477

wWW.rsc.org/dalton

PAPER

\section{Tetrapodal amidoxime ligands I. Coordination isomerism due to self-complementary dimerization of a pyramidal cobalt(III) coordination module $\dagger+$}

\author{
John P. Boyd,* Elisabeth Irran and Andreas Grohmann* \\ Received 29th September 2011, Accepted 21st November 2011 \\ DOI: $10.1039 / \mathrm{c} 2 \mathrm{dt11847e}$
}

\begin{abstract}
A bis- $\mu$-amidoximato-bridged cobalt(III) dimer obtained with a new tetrapodal ligand possesses interesting structural parameters as a consequence of intramolecular hydrogen bonding intentionally built into the complex. Its synthesis and properties are described. The new ligand type combines attributes of two previously described ligand classes: It binds a metal ion in a tetrapodal pentadentate fashion and forms a pseudomacrocycle through hydrogen bonds, characteristic of chelating oxime ligands. Coordination isomerism, which is a consequence of dimer formation, has been analyzed by means of X-ray crystallography and carbon-13 nuclear magnetic resonance spectroscopy.
\end{abstract}

\section{Introduction}

The application of effects arising from peripheral hydrogen bonding in transition metal complexes is of growing importance. Such interactions are instrumental in bioinorganic chemistry and catalysis, where secondary bonding can create a "coordination pocket", tune metal as well as substrate reactivity, stabilize reactive intermediates, and facilitate intra- and intermolecular proton transfer reactions. ${ }^{1,2}$ Two limiting cases of intramolecular hydrogen bonding may be distinguished: $\mathrm{H}$-bonding between a metalcoordinated species and the ligand periphery, ${ }^{3,4}$ and H-bonding within the ligand periphery. ${ }^{5}$ Additionally, hydrogen bonds have been used to incorporate transition metal complexes into host structures, such as cyclodextrins, ${ }^{6}$ and to tune the strength of metal ion extractants. ${ }^{7}$ Methodologies to create ligands that add hydrogen bond-mediated properties to known coordination geometries thus constitute a useful addition to the coordination chemist's toolbox.

Our approach aims at linking equatorial oxime donors via an axial $\mathrm{N}$-heterocycle, thereby generating a tetrapodal pentadentate $\mathrm{N}_{5}$ ligand which forms a square pyramidal coordination environment. The capping ligand thus obtained is reinforced by two hydrogen bonds at the basis of the pyramid. This combination is attractive for at least two reasons: Firstly, pentadentate tetrapodands enforce a donor pattern that may, for reasons of kinetic lability, otherwise be unavailable for first row transition metal complexes; 8 secondly, dioxime ligands can form strong hydrogen bonds resulting in pseudomacrocyclic arrangements. This involves deprotonation, which

Institut für Chemie, Technische Universität Berlin, Straße des 17. Juni 135, 10623, Berlin, Germany

$\dagger$ Electronic supplementary information (ESI) available. CCDC reference numbers 825623-825624. For ESI and crystallographic data in CIF or other electronic format see DOI: 10.1039/c2dt11847e

$\$$ Dedicated to Martin A. Bennett in effect compensates positive charge brought into the compound upon metal ion coordination (formation of an "inner salt").

The connectivity of the oxime functions in a system of our design necessarily differs from that of the well-known glyoxime (i.e. 1,2dioxime) ligands and related pseudomacrocyclic ligands, which have also been used as bridged pairs, especially for coenzyme $B_{12}$ modelling ("cobaloximes", see Fig. 1, 1a, 1c). ${ }^{9}$ While 1,3-dioxime (including malonamidoxime, i.e., 1,3-diamidoxime; 1e) ligands form hydrogen bonds that are energetically ${ }^{10}$ and geometrically ${ }^{11}$ similar to those found in 1,2-dioxime complexes, they lack conjugation and therefore show decreased $\pi$-backbonding character.

Amidoximes (e.g. malonamidoxime ${ }^{12}$ ) are easily prepared from nitriles by reaction with hydroxylamine (Tiemann reaction). ${ }^{13}$ By varying a nucleophilic aromatic substitution methodology that was established in the context of intramolecular [4 +2] DielsAlder/retro-Diels-Alder ring transformations, ${ }^{14}$ we gained access to a pyrimidine-derived nitrile precursor and from it obtained the prototype of a new ligand class (Fig. 1,4). We describe the synthesis of the ligand and the properties of its cobalt(III) complex, and show that the new type of complex possesses features characteristic of both the hydrogen bond-forming dioxime ligands (Fig. 1, 1a, 1c; 1e) and ligands of the tetrapodal pentadentate topology $(2,3){ }^{15,16}$

\section{Experimental}

Research chemicals were obtained from commercial suppliers and used without further purification. THF was saturated with dry dinitrogen, dried over potassium hydroxide for four weeks and used without further purification. Potassium hydroxide (5 wt \%) was dissolved in ethanol and the solution stored for several weeks to decompose 2-butanone present as a denaturing agent; the solvent was then distilled in vacuo. Routine NMR spectra were measured on a Bruker ARX 200 spectrometer, while the ${ }^{13} \mathrm{C}\left\{{ }^{1} \mathrm{H}\right\}$-spectrum of $\mathbf{1 1}$ was measured on a Bruker $\mathrm{AV}$ 
<smiles></smiles>

$\stackrel{1 a}{\text { Marzilli } 1992}$<smiles>CN1CCCN(C)CCN(C)CCCN(C)CC1</smiles>

$1 \mathrm{~b}$

Que 2008

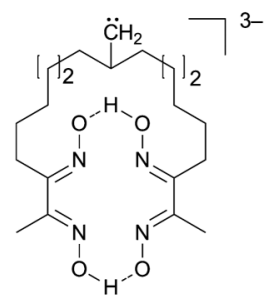

$1 c$

Rétey 1976/1977

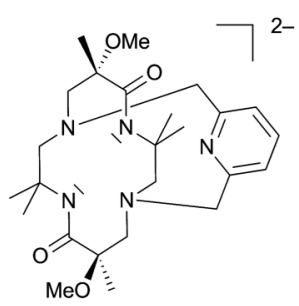

1d

Hegedus 2003<smiles>CCCCC(N)=NOCON=C(N)CC(N)=NOCON=C(N)CC</smiles>

$1 e$

Endres/Elyaderani 1982

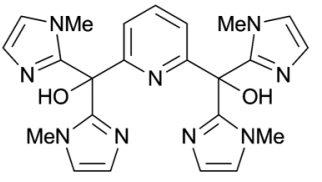

2

Tagaki 1981

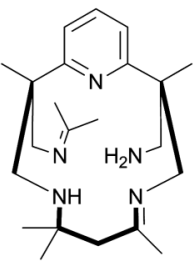

3

Grohmann 2001

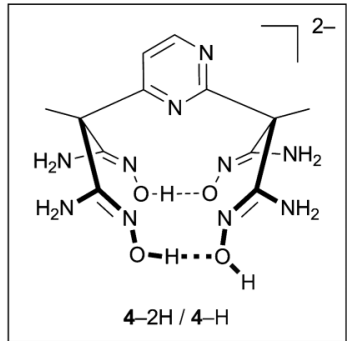

Fig. 1 "Capped" $\left(\mathbf{1 a},{ }^{17} \mathbf{1 b}^{18}\right)$ and "bridged" $\left(\mathbf{1 c},{ }^{9} \mathbf{1 d}^{19}\right)$ pseudomacrocyclic and macrocyclic ligands; conceptual combination of the malonamidoxime pair $\left(\mathbf{1} \mathbf{e}^{11}\right)$ and tetrapodal pentadentate ligands $\left(2,{ }^{15} 3^{16}\right)$ in ligand 4.

400 spectrometer ( $c f$. Fig. 4). EI-MS measurements were conducted using a Finnegan MAT95S instrument. ESI-MS source spectra and collision induced dissociation (CID) spectra were acquired on a Thermo LTQ Orbitrap XL FT-spectrometer (XCalibur software). Combustion analysis was performed using a Thermo Finnigan Flash 1112 apparatus (EAGER 300 software). IR spectra were measured with $\mathrm{KBr}$ disks on a Perkin-Elmer Spectrum 100 Series FT-IR spectrometer. A PAR263A potentiostat was used for electrochemical data acquisition. The quality of iR-drop compensation was analyzed using the RL0 algorithm. ${ }^{20}$ Melting and decomposition points were determined on a Kofler apparatus and calibrated against azobenzene, acetanilide and phenacetine, as applicable. X-ray diffraction: Diffraction data were obtained on an Oxford Diffraction Xcalibur S instrument equipped with a Sapphire CCD-detector using graphite-monochromated Mo$\mathrm{K} \alpha$ radiation with $\lambda=0.71073 \AA$. Suitable crystals were attached to glass fibers using perfluoropolyalkylether oil and transferred to a goniometer where they were cooled to $150 \mathrm{~K}$ for data collection. Software packages used: CrysAlis CCD for data collection, CrysAlis Pro (for cell refinement and data reduction). Empirical absorption corrections (multiscan based on symmetryrelated measurements) were applied using CrysAlis Pro software. ${ }^{21}$ Space groups were determined from systematic absences and confirmed by the successful solution of the structure. Structures were solved by direct methods using the program Sir2004. ${ }^{22}$ Subsequent full-matrix least-squares refinement of $F_{\mathrm{o}}{ }^{2}$ data was carried out using SHELXL-97. ${ }^{23}$ All non-hydrogen atoms were refined anisotropically. Treatment of hydrogen atoms: Carbonbound hydrogen atoms were placed in positions of optimized geometry, and isotropic displacement parameters were tied to those of the corresponding carrier atoms. Oxygen- and nitrogen-bound hydrogen atoms were located in the difference Fourier map and freely refined. Hydrogen atoms belonging to water molecules were refined using distance and angle restraints. Thermal displacement parameters of hydrogen atoms were tied to those of their carrier atoms. Supplementary crystallographic data can be obtained free of charge from The Cambridge Crystallographic Data Centre, CCDC 825623 (10) and CCDC 825624 (11). Molecular graphics were created using Ortep 3v2. ${ }^{24}$

\section{Methylmalonamide (6)}

2-Pyridone ( $1 \mathrm{~g}, 1 \mathrm{~mol} \%)^{25}$ was dissolved in $30 \%$ aqueous ammonia $(400 \mathrm{~mL})$, diethyl methylmalonate $(5)$ added $(200 \mathrm{~mL}, 1.16 \mathrm{~mol}$, $202 \mathrm{~g}$ ), and the biphasic reaction mixture stirred vigorously overnight. A fine colourless precipitate was collected on a Buchner funnel, washed with ethanol, and dried overnight in air. Colourless solid (80 g, 60\%).

Mp. 209-211 ${ }^{\circ} \mathrm{C}$ (lit. ${ }^{26} 210{ }^{\circ} \mathrm{C}$ ). Anal. found: C, 41.67, H, 7.11, $\mathrm{N}, 24.19 \%$, calcd for $\mathrm{C}_{4} \mathrm{H}_{8} \mathrm{~N}_{2} \mathrm{O}_{2}: \mathrm{C}, 41.37, \mathrm{H}, 6.94, \mathrm{~N}, 24.12 \% .{ }^{1} \mathrm{H}-$ NMR (d ${ }^{6}$-DMSO): 7.23 (s br, 2 H, NH), 6.98 (s br, 2 H, NH), 3.06 $\left(\mathrm{q},{ }^{3} J(\mathrm{HH})=7.2 \mathrm{~Hz}, 1 \mathrm{H}, \mathrm{CH}\right), 1.55\left(\mathrm{~d},{ }^{3} J(\mathrm{HH})=7.2 \mathrm{~Hz}, 3 \mathrm{H}\right.$, $\left.\mathrm{CH}_{3}\right) ;{ }^{13} \mathrm{C}-\mathrm{NMR}$ (d $\mathrm{d}^{6}$-DMSO): $172.4(\mathrm{CO}), 46.7(\mathrm{CH}), 15.0\left(\mathrm{CH}_{3}\right)$; EI-MS $\left(70 \mathrm{eV}, 120{ }^{\circ} \mathrm{C}\right): 116\left(\mathrm{M}^{+}, \sim 3 \%\right), 99\left(\mathrm{M}-\mathrm{NH}_{3}, \sim 2 \%\right), 73$ $(\mathrm{M}-\mathrm{HOCN}, 100 \%), 55(\mathrm{M}-\mathrm{HOCN} / \mathrm{CO}, 20 \%), 44\left(\mathrm{CONH}_{2}{ }^{+}\right.$, 50\%); IR: $1674 \mathrm{~cm}^{-1}(\mathrm{CO})$.

\section{Methylmalononitrile (7)}

The compound was prepared according to a literature procedure ${ }^{26}$ by reactive vacuum dehydration/distillation of methylmalonamide (6) over phosphorous pentoxide at $15 \mathrm{~mm} \mathrm{Hg} / 250{ }^{\circ} \mathrm{C}$. Colourless solid, max. yield $65 \%$.

Mp. $35^{\circ} \mathrm{C}$ (lit. ${ }^{27} 32-36{ }^{\circ} \mathrm{C}$ ). Anal. found: C, 59.82, H, 4.55, N, $35.18 \%$, calcd for $\mathrm{C}_{4} \mathrm{H}_{4} \mathrm{~N}_{2}$ : C, 59.99, H, 5.03, N. 34.98\%. ${ }^{1} \mathrm{H}-\mathrm{NMR}$ $\left(\mathrm{CDCl}_{3}\right): 3.80\left(\mathrm{q},{ }^{3} J(\mathrm{HH})=7.3 \mathrm{~Hz}, 1 \mathrm{H}, \mathrm{CH}\right), 1.79\left(\mathrm{~d},{ }^{3} J(\mathrm{HH})=7.3\right.$ $\left.\mathrm{Hz}, 3 \mathrm{H}, \mathrm{CH}_{3}\right) ;{ }^{13} \mathrm{C}-\mathrm{NMR}\left(\mathrm{CDCl}_{3}\right): 113.0(\mathrm{CN}), 16.7(\mathrm{CH}), 16.5$ $\left(\mathrm{CH}_{3}\right)$; EI-MS $\left(70 \mathrm{eV}, 29^{\circ} \mathrm{C}\right): 79(\mathrm{M}-1,40 \%), 53(\mathrm{M}-\mathrm{HCN}, 95 \%)$, $28\left(\mathrm{HCNH}^{+}, 100 \%\right)$; IR: $2262 \mathrm{~cm}^{-1}$ (CN) (lit. $\left.{ }^{27} 2255-2260 \mathrm{~cm}^{-1}\right)$. 


\section{2,4-Dichloropyrimidine (9)}

In a $250 \mathrm{~mL}$ flask, uracil $(5.0 \mathrm{~g}, 45 \mathrm{mmol})$ and tetraethyl ammonium chloride $(1.1 \mathrm{~g}, 15 \mathrm{~mol} \%)$ were suspended in phosphorous oxychloride $(10 \mathrm{~mL})$, and heated to $120{ }^{\circ} \mathrm{C}$ for $1 \mathrm{~h}$ (CAUTION: vigorous evolution of hydrogen chloride gas). The mixture was subsequently allowed to cool, while stirring was continued overnight. The brown solution was poured on crushed ice (100 g) and stirred until a yellowish solid appeared. The solid was collected at $0{ }^{\circ} \mathrm{C}$ by filtration (CAUTION: The hydrolysis of phosphorous oxychloride at $0{ }^{\circ} \mathrm{C}$ is incomplete; a strongly exothermic reaction occurs in the aqueous filtrate upon warming) and washed with ice water, dissolved in chloroform $(80 \mathrm{~mL})$, dried over sodium sulfate and filtered through neutral alumina (IIIII). After volatiles had been removed in vacuo, the residual oil crystallized upon cooling. Yellowish rods (2.4 g, 36\%).

Mp. $61{ }^{\circ} \mathrm{C}$ (lit. $.^{28} 61-62{ }^{\circ} \mathrm{C}$ ). Anal. found: C, 32.89, H, 1.37, N, $18.88 \%$, calcd for $\mathrm{C}_{4} \mathrm{H}_{2} \mathrm{~N}_{2} \mathrm{Cl}_{2}: \mathrm{C}, 32.25, \mathrm{H}, 1.35, \mathrm{~N}, 18.80 \% .{ }^{1} \mathrm{H}-$ $\operatorname{NMR}\left(\mathrm{CDCl}_{3}\right): 8.53\left(\mathrm{~d},{ }^{3} \mathrm{~J}=5.3 \mathrm{~Hz}, 1 \mathrm{H}\right), 7.35\left(\mathrm{~d},{ }^{3} J=5.3 \mathrm{~Hz}, 1 \mathrm{H}\right)$; ${ }^{13} \mathrm{C}-\mathrm{NMR}\left(\mathrm{CDCl}_{3}\right): 162.7$ and $161.0(\mathrm{CCl}), 160.0$ and $120.3(\mathrm{CH})$; HR-EI-MS (370 K) M+ calcd: $147.95950 \mathrm{~m} / \mathrm{z}$; found: 147.95919 $m / z$.

\section{2,2'-(Pyrimidine-2,4-diyl)bis(2-methylmalononitrile) (10)}

Under an atmosphere of dry dinitrogen, commercial lithium hydride $(640 \mathrm{mg}, 80 \mathrm{mmol})$ was suspended in dry THF $(20 \mathrm{~mL})$ at $20{ }^{\circ} \mathrm{C}$ with stirring, in a reaction flask on a water bath. A solution of methylmalononitrile (7) $(6.57 \mathrm{~g}, 82 \mathrm{mmol})$ in THF $(15 \mathrm{~mL})$ was added during $15 \mathrm{~min}$, which resulted in hydrogen evolution. The temperature was maintained between 25 and $35^{\circ} \mathrm{C}$ during addition. After the evolution of hydrogen had ceased, a slightly yellow solution had formed. The water bath was replaced with an oil bath, and a solution of 2,4-dichloropyrimidine (9) $(5.97 \mathrm{~g}$, $40 \mathrm{mmol})$ in THF $(5-10 \mathrm{~mL})$ was added rapidly. The exothermic reaction warmed the mixture to $70{ }^{\circ} \mathrm{C}$ instantaneously, and the oil bath was then heated to hold the reaction mixture at reflux temperature for an additional $30 \mathrm{~min}$. A precipitate formed in the course of the reaction. The mixture was allowed to cool to room temperature and then quenched with water $(10 \mathrm{~mL})$ to dissolve precipitated lithium chloride. Concentrated aqueous ammonium chloride solution $(20 \mathrm{~mL})$ and dichloromethane $(50 \mathrm{~mL})$ were added subsequently. The phases were separated, and the aqueous phase extracted with additional dichloromethane $(20 \mathrm{~mL})$. The combined extracts were dried over sodium sulfate, filtered over neutral alumina (II-III), and volatiles were removed in vacuo. The remaining oil (8.9 g, 94\%) crystallized rapidly. Melting point and elemental analysis data (below) were determined for this material, and it was also used in the subsequent synthetic steps without further purification. The material can be recrystallized from a tenfold amount of benzene to yield $\mathbf{1 0}$ as a colourless crystalline solid (cf. Table 1).

Mp. (unrecrystallized material): $112{ }^{\circ} \mathrm{C}$; Anal. found (unrecrystallized material): C, $60.13, \mathrm{H}, 3.47, \mathrm{~N}, 35.25 \%$, calcd for $\mathrm{C}_{12} \mathrm{H}_{8} \mathrm{~N}_{6}$ : $\mathrm{C}, 61.01, \mathrm{H}, 3.41, \mathrm{~N}, 35.58 \% .{ }^{1} \mathrm{H}-\mathrm{NMR}\left(\mathrm{CDCl}_{3}\right): 9.12\left(\mathrm{~d},{ }^{3} J=5.2\right.$ $\mathrm{Hz}, 1 \mathrm{H}, \mathrm{CH}), 7.89$ (d, $\left.{ }^{3} \mathrm{~J}=5.3 \mathrm{~Hz}, 1 \mathrm{H}, \mathrm{CH}\right), 2.29(\mathrm{~s}, 3 \mathrm{H}$, $\left.\mathrm{CH}_{3}\right), 2.26\left(\mathrm{~s}, 3 \mathrm{H}, \mathrm{CH}_{3}\right) ;{ }^{13} \mathrm{C}-\mathrm{NMR}\left(\mathrm{CDCl}_{3}\right): 162.8$ and 161.9 (quaternary aromatic $\mathrm{C}$ ), 161.6 and $118.1(\mathrm{CH}), 113.7$ and 113.2 (CN), 40.3 and 37.9 (quaternary aliphatic C), 26.4 and $26.3\left(\mathrm{CH}_{3}\right)$; HR-EI-MS (370 K): $\mathrm{M}^{+}$calcd: $236.08104 \mathrm{~m} / \mathrm{z}$; found: 236.07989 $m / z$; IR: $2260 \mathrm{~cm}^{-1}(\mathrm{CN})$.

\section{2,2'-(Pyrimidine-2,4-diyl)bis(N'1,N'3-dihydroxy-2- methylmalonamidoxime) (4)}

Unrecrystallized nitrile $\mathbf{1 0}(7.91 \mathrm{~g}, 33 \mathrm{mmol})$ was crushed into small pieces and suspended in ethanol $(50 \mathrm{~mL}$; purified to remove 2-butanone). Aqueous hydroxylamine ( $50 \mathrm{wt} \%, 10 \mathrm{~mL}, 166 \mathrm{mmol})$ was added. The nitrile began to dissolve after a brief initiation period, and an exothermic reaction brought the mixture to reflux. A precipitate formed. The mixture was left to cool and stirred for an additional $24 \mathrm{~h}$ at room temperature. The precipitate was collected, washed with a small amount of ethanol and dried in air. Very fine colourless powder $(10 \mathrm{~g}, 85 \%)$, decomposes at $\sim 190{ }^{\circ} \mathrm{C}$.

Table 1 Summary of crystallogaphic data

\begin{tabular}{lll}
\hline Empirical formula & $\mathrm{C}_{12} \mathrm{H}_{8} \mathrm{~N}_{6}(\mathbf{1 0})$ & $\mathrm{C}_{32} \mathrm{H}_{62} \mathrm{Co}_{2} \mathrm{~F}_{12} \mathrm{~N}_{20} \mathrm{O}_{28}\left(\mathbf{1 1} \cdot 12 \mathrm{H}_{2} \mathrm{O}\right)$ \\
\hline Formula weight & 236.34 & 1520.88 \\
$T / \mathrm{K}$ & $150(2)$ & $150(2)$ \\
$\lambda / \AA$ & 0.71073 & 0.71073 \\
Crystal system & Monoclinic & Triclinic \\
Space group & $P 2_{1} / n$ & $P \overline{1}$ \\
$a / \AA, h / \AA, c / \AA$ & $6.6056(2), 10.9046(4), 16.8884(5)$ & $9.2213(4), 12.9948(6), 13.4621(8)$ \\
$\alpha\left({ }^{\circ}, \beta\left({ }^{\circ}\right), \gamma\left({ }^{\circ}\right)\right.$ & $90,97.859(3), 90$ & $69.118(5), 83.997(4), 73.435(4)$ \\
$U / \AA^{3}$ & $1205.07(7)$ & $1444.63(12)$ \\
$Z$ & 4 & 1 \\
$D_{\mathrm{c}} / \mathrm{Mg} \mathrm{m}^{-3}$ & 1.302 & 1.748 \\
$\mu / \mathrm{mm}^{-1}$ & 0.086 & 0.716 \\
$F(000)$ & 488 & 780 \\
Crystal size/mm & $0.60 \times 0.33 \times 0.30$ & $0.40 \times 0.22 \times 0.11$ \\
$\Theta$ range/ ${ }^{\circ}$ & 3.07 to 25.00 & 3.28 to 25.00 \\
Range $h, k, l$ & -7 to $7,-12$ to $12,-17$ to 20 & -10 to $10,-12$ to $15,-11$ to 15 \\
Independent reflections & $2107[R(\mathrm{int})=0.0185]$ & $5065[R($ int $)=0.0292]$ \\
Data/restraints/parameters & $2107 / 16 / 181$ & $5065 / 110 / 535$ \\
Goodness-of-fit on $F^{2}$ & 1.045 & 0.973 \\
Final $R$ indices $[I>2 \sigma(I)]$ & $R_{1}=0.0349, \mathrm{w} R_{2}=0.0760$ & $R_{1}=0.0389, \mathrm{w} R_{2}=0.0892$ \\
$R$ indices (all data) & $R_{1}=0.0473, \mathrm{w} R_{2}=0.0800$ & $R_{1}=0.0534, \mathrm{w} R_{2}=0.0928$ \\
Largest diff. peak and hole/e $\AA^{-3}$ & 0.148 and -0.146 & 0.555 and -0.327 \\
\hline
\end{tabular}


Anal. found: $\mathrm{C}, 40.03, \mathrm{H}, 5.73, \mathrm{~N}, 37.27 \%$, calcd for $\mathrm{C}_{12} \mathrm{H}_{20} \mathrm{~N}_{10} \mathrm{O}_{4}$ : C, 39.13, H, 5.47, N, 38.03\%. ${ }^{1} \mathrm{H}-\mathrm{NMR}\left(\mathrm{d}_{6}\right.$-DMSO): 9.36 (s br, $2 \mathrm{H}, \mathrm{OH}), 9.23$ (s br, $2 \mathrm{H}, \mathrm{OH}), 8.65\left(\mathrm{~d},{ }^{3} J(\mathrm{HH})=\right.$ $5.3 \mathrm{~Hz}, 1 \mathrm{H}, \mathrm{CH}), 7.31\left(\mathrm{~d},{ }^{3} J(\mathrm{HH})=5.3 \mathrm{~Hz}, 1 \mathrm{H}, \mathrm{CH}\right), 5.32$ (s br, $4 \mathrm{H}, \mathrm{NH}$ ), 5.23 (s br, $4 \mathrm{H}, \mathrm{NH}$ ), 1.71 (s, $3 \mathrm{H}, \mathrm{CH}_{3}$ ), 1.65 (s, $\left.3 \mathrm{H}, \mathrm{CH}_{3}\right)$; selected 2D ${ }^{1} \mathrm{H}-{ }^{1} \mathrm{H}$ NOESY cross peaks: 7.31/1.65 (pyrimidine-C5-H/methyl), 1.65/5.32 (methyl/amino), 5.32/9.36 (amino/hydroxyl); ${ }^{13} \mathrm{C}-\mathrm{NMR}$ ( $\mathrm{d}_{6}$-DMSO): 169.67 and 168.21 (quaternary aromatic $\mathrm{C}$ ), $157.26(\mathrm{CH}), 155.18$ and 154.53 (quaternary oxime $\mathrm{C}$ ), 119.21(CH), 54.30 and 52.74 (quaternary aliphatic C), 22.11 and $21.89\left(\mathrm{CH}_{3}\right)$; HR-ESI-MS (RT): $\mathrm{MH}^{+}$ calcd: $369.17418 \mathrm{~m} / \mathrm{z}$; found: $369.17334 \mathrm{~m} / \mathrm{z}$; IR: 1676 and 1657 $\left(\mathrm{C}=\mathrm{N}_{\text {oxime }}\right), 947$ and $935(\mathrm{~N}-\mathrm{O})$.

\section{$\left\{\mathrm{Co}^{\mathrm{III}}{ }_{2}[4-\mathrm{H}]_{2}\right\}\left(\mathrm{OCOCF}_{3}\right)_{4}(11)$}

In air, solid 4 (830 mg, $2.25 \mathrm{mmol})$ and solid cobalt(II) acetate tetrahydrate $(560 \mathrm{mg}, 2.25 \mathrm{mmol})$ were dissolved in a stirred mixture of trifluoroacetic acid $(2 \mathrm{~mL})$ and ethanol $(10 \mathrm{~mL})$ at room temperature. The brown solution that formed was stirred for $1 \mathrm{~h}$ and then poured on cold diethylether $\left(40 \mathrm{~mL}, 5^{\circ} \mathrm{C}\right)$. An orange-brown solid was collected by filtration, washed with cold diethylether $(30 \mathrm{~mL})$, and dried in vacuo $(690 \mathrm{mg}, 47 \%)$. Additional product can be obtained by slow evaporation of the filtrate. The exchange of acetate for trifluoroacetate proceeds to approx. $93 \%$, as estimated from the resonance of remaining acetate in the ${ }^{1} \mathrm{H}$ NMR spectrum. 11 decomposes at $150{ }^{\circ} \mathrm{C}$.

Anal. found: C, 29.70; H, 2.65; N, 20.88\%, calcd for $\mathrm{C}_{32} \mathrm{H}_{38}$

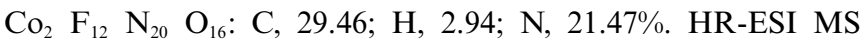
$(\mathrm{MeOH} ; m / z ; \%):\left[\mathrm{Co}_{2}{ }_{2}(4-2 \mathrm{H})_{2}\right]^{2+}(425.08(3) ; 100 \%),\left\{\left[\mathrm{Co}^{\mathrm{III}}(4\right.\right.$ $\left.-2 \mathrm{H})]_{2}\left(\mathrm{OCOCF}_{3}\right)\right\}^{+}(963.15(3) ; 10 \%),\left[\mathrm{Co}^{\mathrm{III}}{ }_{2}(4-2 \mathrm{H})(4-3 \mathrm{H})\right]^{+}$ (849.15(9); 5\%), $\left\{\mathrm{Co}^{\mathrm{III}}(4-\mathrm{H})\left(\mathrm{OCOCF}_{3}\right)\right\}^{+}(539.07(6) ;<1 \%)$; ${ }^{1} \mathrm{H}-\mathrm{NMR}\left(\mathrm{d}_{6}\right.$-DMSO): $9.70(\mathrm{~m}, 1 \mathrm{H}, \mathrm{OH}), 9.09\left(\mathrm{~d},{ }^{3} J(\mathrm{HH})=\right.$ $6 \mathrm{~Hz}, 1 \mathrm{H}, \mathrm{CH}), 7.85\left(\mathrm{~d},{ }^{3} \mathrm{~J}(\mathrm{HH})=6 \mathrm{~Hz}, 1 \mathrm{H}, \mathrm{CH}\right), 8.20$, 7.54, 7.35, 7.08 (four s br, $8 \mathrm{H}, \mathrm{NH}$ ), 2.12, 2.08 (two s br, $6 \mathrm{H}$, $\mathrm{CH}_{3}$ ). The compound was dissolved in absolute trifluoroacetic acid, dried in vacuo and crystallized by slow evaporation of a highly dilute aqueous solution at $5{ }^{\circ} \mathrm{C}$ to obtain single crystals of the dodecahydrate $\left(\mathbf{1 1} \cdot 12 \mathrm{H}_{2} \mathrm{O}\right)$ suitable for X-ray diffraction measurements ( $c f$. Table 1).

\section{Results and discussion}

\section{Ligand and complex synthesis}

Methylmalononitrile (7) was prepared from 5 in a sequence of ester ammonolysis and dehydration. ${ }^{26}$ The published procedure for the preparation of methylmalondiamide (6) was modified in two ways: 2-Pyridone was used as a bifunctional catalyst, ${ }^{25}$ and aqueous ammonia as the solvent instead of a mixture of methanol and liquid ammonia. This decreases the yield (from $99 \%$, as published, to $60 \%$ ), but the reaction time is shortened considerably (from several weeks to $12 \mathrm{~h}$ ). Uracil (8) is converted to 2,4dichloropyrimidine (9) by the action of phosphorous oxychloride. We modified the available procedures ${ }^{28}$ (see Experimental section) by using tetraalkylammonium chlorides instead of aniline derivatives as additives. Specifically, the reaction product contained less of a lachrymatory impurity when the exposure of uracil to hot phosphorous oxychloride was limited to $1 \mathrm{~h}$.

Chlorodiazines are highly reactive with respect to nucleophilic aromatic substitution of the $\mathrm{Cl}$ substituents by deprotonated geminal dinitriles. ${ }^{14}$ In our case, the reaction of the lithium salt of methylmalononitrile with 2,4-dichloropyrimidine (9) in THF produces tetranitrile 10. The lithium salt of 7 is conveniently prepared at temperatures above $15{ }^{\circ} \mathrm{C}$ by the reaction with commercial lithium hydride. The reaction is relatively insensitive to moisture which can be attributed to the low $\mathrm{p} K_{\mathrm{a}}$ of geminal dinitriles, ${ }^{29}$ their high nucleophilicity ${ }^{30}$ and the essential inertness of commercial $\mathrm{LiH}^{31} \mathbf{1 0}$ is converted to the corresponding tetraamidoxime (4) by reaction with aqueous hydroxylamine in ethanol (Fig. 2). Although the addition of hydroxylamine to this nitrile is an exothermic reaction, the four-fold addition goes to near completion only upon prolonged exposure of the tetranitrile to hydroxylamine solution at room temperature, owing to the low solubility of the higher addition products. Combustion analysis and ESI-MS indicate that three-fold addition products are present in the compound as minor impurities. ${ }^{1} \mathrm{H}-\mathrm{NMR}$ spectroscopy $\left(\mathrm{d}_{6}\right.$-DMSO) shows well-resolved signals of the magnetically inequivalent methyl, hydroxyl and amide groups (see Supporting information $\dagger$ ). Ligand $\mathbf{4}$ is sparingly soluble in common laboratory solvents and may be stored in air for extended periods of time without decomposition. It decomposes with evolution of gas when heated above $190{ }^{\circ} \mathrm{C}$. Although no adverse behaviour was observed in the course of our study, it should be noted that oximes generally pose a fire and explosion hazard. Attempts to prepare cobalt(II) compounds of $\mathbf{4}$ under conditions otherwise known to produce cobaloximes failed, and we propose reasons for this in the following. In air, however, a rapid reaction occurs between cobalt(II)acetate tetrahydrate and $\mathbf{4}$, and a cobalt(III) compound is formed. In the presence of excess trifluoroacetic acid, the carboxylate counter ions are exchanged, and $\mathbf{1 1}$ is obtained which forms single crystals of its dodecahydrate upon slow evaporation of water from the aqueous solution at $5{ }^{\circ} \mathrm{C}\left(\mathbf{1 1} \cdot 12 \mathrm{H}_{2} \mathrm{O}\right.$, cf. Fig. 3 and Fig. 6).
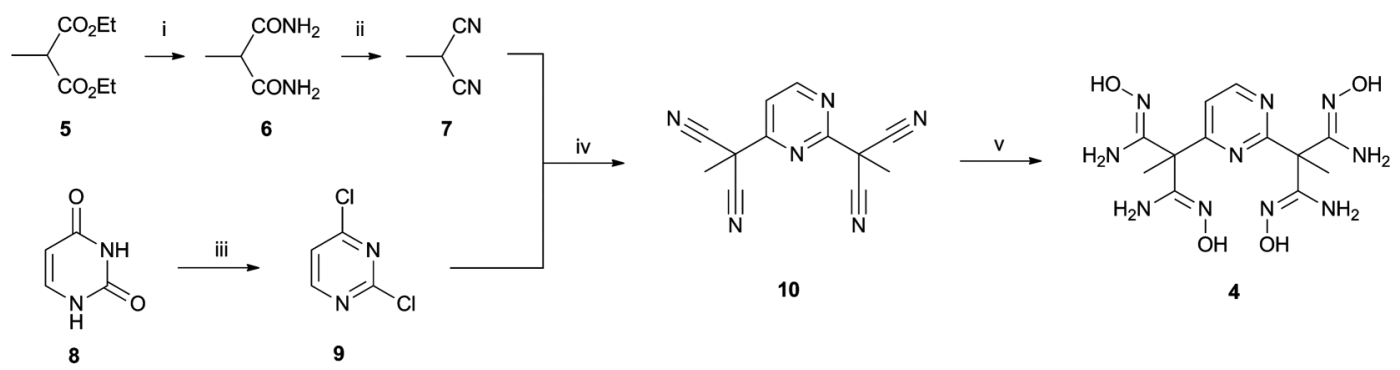

Fig. 2 i) $\mathrm{NH}_{4} \mathrm{OH}$, cat. 2-pyridone, rt, $24 \mathrm{~h}, 60 \%$; ii) $\mathrm{P}_{2} \mathrm{O}_{5}$ on sand, $250{ }^{\circ} \mathrm{C}, 15$ torr, $65 \%$; iii) $\mathrm{POCl}_{3}, \mathrm{NEt}_{4} \mathrm{Cl}, 120{ }^{\circ} \mathrm{C}, 1 \mathrm{~h}, 36 \%$; iv) $\mathrm{LiH}$, THF, reflux, 45 min, 94\%; v) $\mathrm{NH}_{2} \mathrm{OH}$, EtOH, 24 h, $85 \%$. 

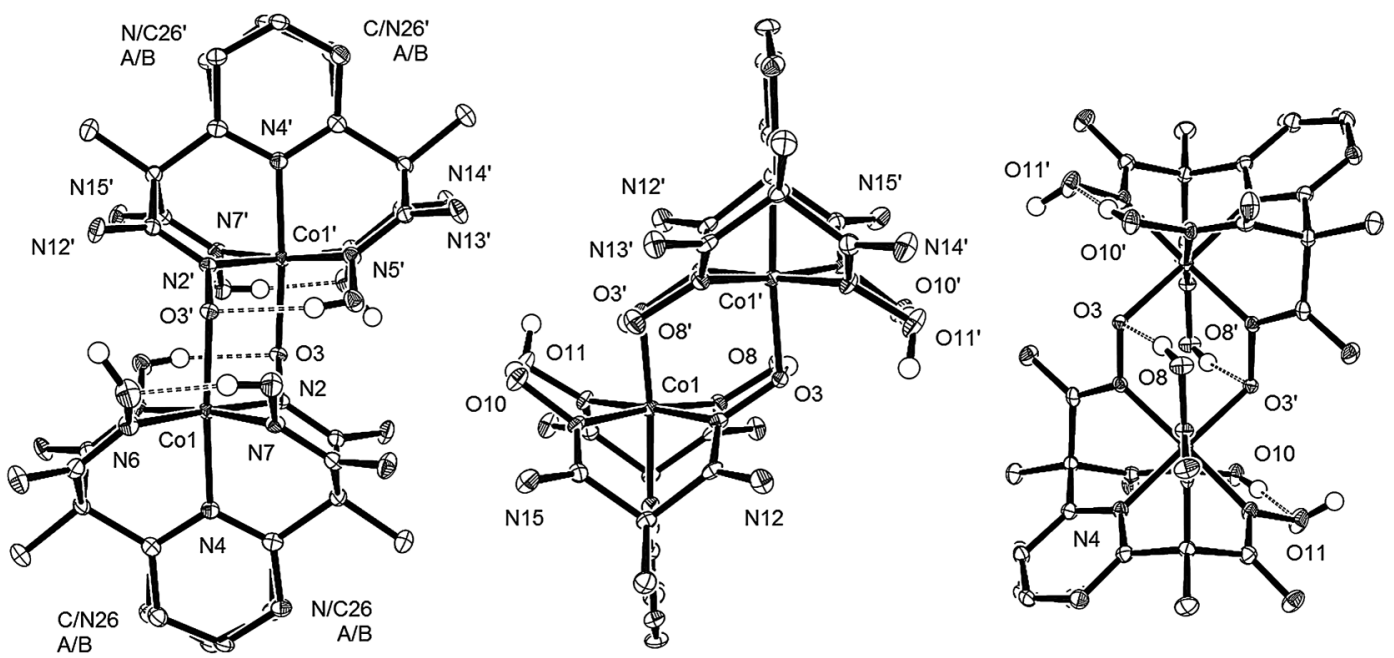

Fig. 3 Three different views of the disordered structure of the formal tetracation in $\mathbf{1 1} \cdot 12 \mathrm{H}_{2} \mathrm{O}$ (ellipsoids at the $50 \%$ probability level; $c f$. Fig. 5; primed symbols refer to equivalent positions $1-x, 1-y, 1-z$ ).

\section{Oxidation pathways}

The ligand does not dissolve in the reaction mixture when its complexation is attempted in the absence of oxygen. When micromolar amounts of $\mathbf{4}$ and cobaltous acetate are mixed in a 1:1 molar ratio at high dilution in the absence of additional trifluoroacetic acid in air, an instantaneous reaction occurs, producing an orange solution. ESI mass spectra of this crude mixture are dominated by an ion of the composition $\left[\mathrm{Co}^{\mathrm{III}}{ }_{2}(4-2 \mathrm{H})_{2}\right]^{2+}$ which is also dominant in ESI spectra of the purified compound. Additionally, a trinuclear cluster $\left[\mathrm{Co}_{3}\left(\mathrm{O}_{2}\right)(4-2 \mathrm{H})_{2}\right]^{+}$accompanied by a protonated dication $\left[\mathrm{Co}_{3}\left(\mathrm{O}_{2}\right)(4-2 \mathrm{H})(4-\mathrm{H})\right]^{2+}$ is observed which is not present in the spectra of material prepared in the presence of trifluoroacetic acid. CID (collision-induced dissociation) experiments with the monocation reveal interesting behaviour, as only the simultaneous loss of two water molecules is observed at high collision energies, whereas a signal corresponding to the loss of a single water molecule is not observed. It is therefore unlikely that $\mathbf{4}$ first coordinates $\mathrm{Co}$ (II) in square-pyramidal fashion and then reacts with molecular oxygen. Rather, the data points to a complex acidpromoted oxidation mechanism involving cluster compounds that are finally trapped in the form of the very stable "quasi-cryptand" dimer described in the following. The cobalt(III) compound shows an irreversible reduction peak in its cyclic voltammogram (dry DMF, $298 \mathrm{~K}, 50-800 \mathrm{mV} \mathrm{s}^{-1}$, glassy carbon working electrode) at voltages more negative than $-2.7 \mathrm{~V} v$ s. ferrocene. This unexpected recalcitrance with respect to stabilization of cobalt(II) can be explained by the lack of $\pi$-backbonding in $\alpha, \gamma$-dioximes and the rigidity of the dimer which cannot easily accommodate an increase in ionic radius.

\section{Structural analysis (part 1)}

$\mathrm{X}$-ray structural analysis revealed a complex of the composition $\left[\mathrm{Co}_{2}{ }_{2}(4-\mathrm{H})_{2}\right]\left(\mathrm{OCOCF}_{3}\right)_{4} \cdot 12 \mathrm{H}_{2} \mathrm{O}\left(\mathbf{1 1} \cdot 12 \mathrm{H}_{2} \mathrm{O}\right)$. The dinuclear tetracation contains two capping ligands, each of which is deprotonated at one of its hydroxyl groups, forming a bis- $\mu$-amidoximatobridged core (Fig. 3). The orientation of the pyrimidine heterocycle (the uncoordinated nitrogen atom may be in one of two different positions) could not be assigned unambiguously on the basis of the diffraction data. In $P \overline{1}$, the asymmetric unit contains one disordered half of the dimer that is related to the other half by a centre of symmetry. A similar disorder was encountered during refinement of the crystal structure of the tetranitrile precursor 10 (see Supporting information $\dagger$ ). Both possible orientations (with respect to one cobalt ion) produced unexceptional thermal ellipsoids in $P 1$ as well as in $P \overline{1}$ but, in the difference Fourier map, had residual electron density in the vicinity of the atom assigned as carbon ( $c f$. Fig. 4). Although the structure, as discussed in the following, represents an average, the thermal ellipsoids are unexceptional. Disorder in $\mathbf{1 1}$ can be explained by invoking the presence of four stereoisomeric forms. Of these, two are centrosymmetric ( $c f$. Fig. $4, \mathrm{~B}$ and $\mathrm{C}$ ), and the remaining two are a pair of enantiomers ( $c f$. Fig. 4, A and A*). In the following, we discuss three limiting cases, i)-iii); i) Only one enantiomer, A or $\mathrm{A}^{*}$, is present (spontaneous racemate resolution). Then, a solution in $P \overline{1}$ necessarily leads to a diagnosis of pseudosymmetry; ii) both $\mathrm{A}$ and $\mathrm{A}^{*}$ are present. In this case, a solution in $P \overline{1}$ leads to a diagnosis of pseudosymmetry and disorder; the disorder, however, could only be solved in the lower-symmetric space group $P 1$; iii) all four stereoisomeric forms are present, such that the observed pseudosymmetry contains both point groups, $C_{1}$ and $C_{\mathrm{i}}$. Then, the observed stereoisomerism cannot be resolved in a centrosymmetric space group due to the presence of noncentrosymmetric enantiomers. For this reason, the site occupancy factors of the isomers were refined in $P 1$ for comparison. The chiral forms A and A* (Fig. 4) converged to approximately $75 \%$ of the whole, indicating isomerism. By restraining the occupation of the 1- and 5-positions of the pyrimidine ring to $50: 50(\mathrm{~N}: \mathrm{CH})$ each, a disordered solution in $P \overline{1}$ was obtained as a compromise, because refinement in $P 1$ was not feasible without strongly restraining the atomic displacement parameters. Within this solution, identical $\mathrm{CH}$ distances (within estimated standard deviations) were determined for both disordered positions, whereas $\mathrm{H}$ atoms collapsed on their carrier atoms, with unrealistic distances, when the disorder was ignored. This solution is compatible with all limiting cases i)-iii). 

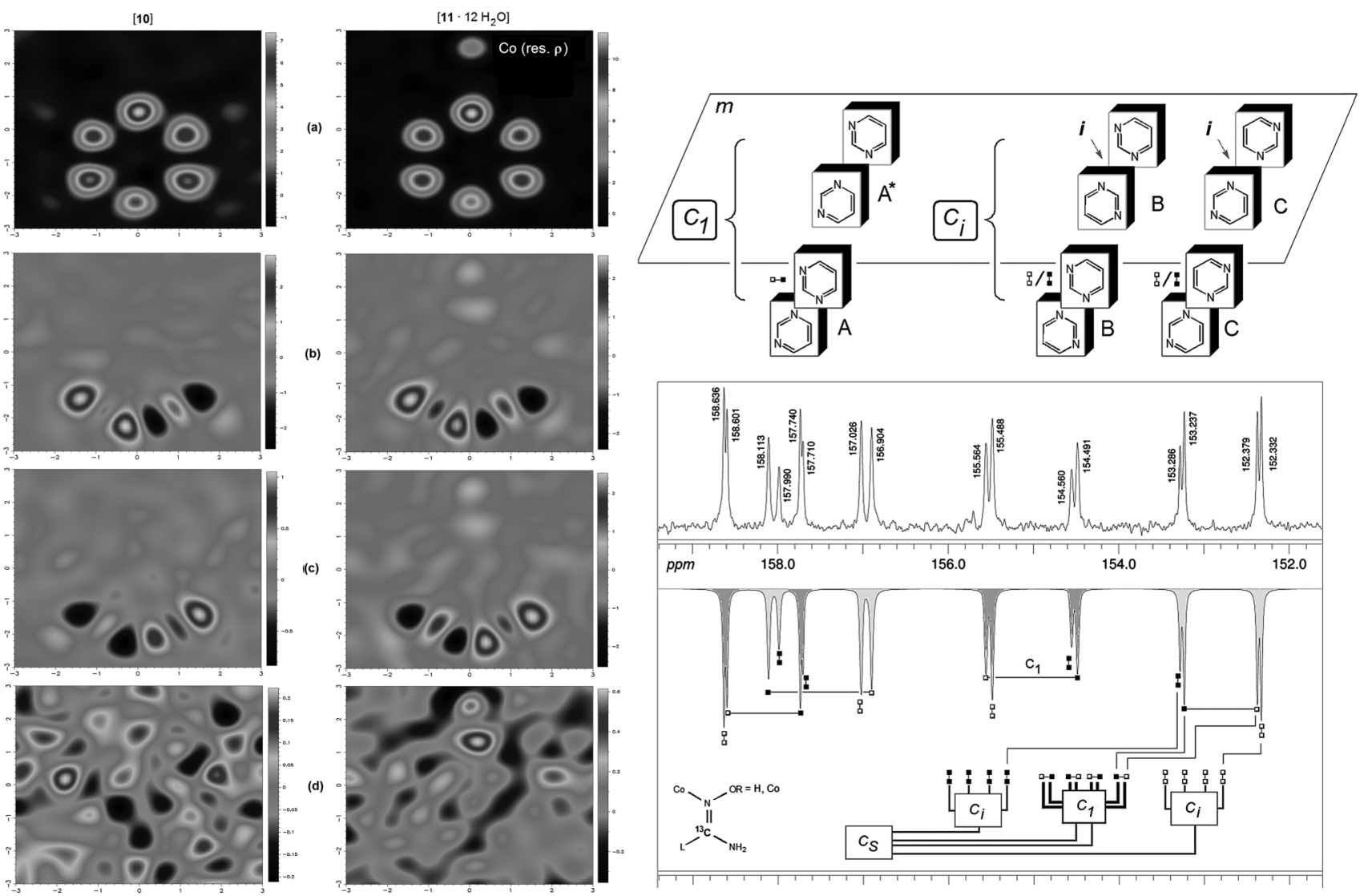

Fig. 4 Electron density maps of the pyrimidine plane in $\mathbf{1 0}$ and $\mathbf{1 1} \cdot 12 \mathrm{H}_{2} \mathrm{O}$; (a) experimental electron density; (b/c) residual density resulting from ignored disorder; (d) minor fluctuation in the difference density maps of the solutions incorporating disorder, with peaks occurring at bonding critical points (note the different scales). The position of the cobalt ion (residual electron density) can be seen in figure (a) (at right). (e) Top: Possible stereoisomers in 11 ( $m$ denotes a mirror plane, $i$ a centre of symmetry and $A^{*}$ an enantiomer). Below: Symmetry interpretation of the ${ }^{13} \mathrm{C}\left\{{ }^{1} \mathrm{H}\right\}-\mathrm{NMR}(100 \mathrm{MHz})$ signals assigned to amidoxime groups of $\mathbf{1 1}$ in $\mathrm{D}_{2} \mathrm{O}$ (cf. Fig. 3).

\section{Coordination isomerism and ${ }^{13} \mathrm{C}\left\{{ }^{1} \mathrm{H}\right\}-\mathrm{NMR}$ (in $\mathrm{D}_{2} \mathrm{O}$ )}

Unlike ligand 4, ligands of the tetrapodal pentadentate class usually have $C_{2 \mathrm{v}}$ point group symmetry, which renders all equatorial donor functions magnetically equivalent. In ligand 4, the "true" point group is $C_{\mathrm{s}}$, the only symmetry element other than identity being a mirror plane which coincides with the pyrimidine ring plane, i.e., the two-fold rotation axis, as found in $C_{2 \mathrm{v}}$, is missing. However, the breaking of symmetry in 4 occurs not in the first coordination sphere but in the ligand periphery, as all equatorial donor functions are amidoxime groups. Therefore, we may call 4 "pseudo$C_{2 \mathrm{v}}$ symmetric", i.e. dimerization can still occur with monomers having their pyrimidine rings in every possible orientation ( $c f$. Fig. 4). For a truely $C_{2 v}$ symmetric ligand, dimerization of the present kind would result in a dimer belonging to point group $C_{\mathrm{i}}$. This means that in each monomeric motif, all four amidoxime functions would have a slightly different chemical environment, but each environment would occur twice per molecule, as a consequence of inversion symmetry. Consequently, this point group occurs only in two out of four conceivable cases for a "pseudo- $C_{2 \mathrm{v}}$ symmetric", in actual fact $C_{\mathrm{s}}$ symmetric, ligand. These two cases are composed of two different isomers that have different chemical environments. The other two cases show $C_{1}$ point group symmetry and are a pair of enantiomers, such that all eight amidoxime functions have slightly different chemical environments. Taking into consideration the previous explanations for an isomeric mixture of four different compounds, 16 different ${ }^{13} \mathrm{C}\left\{{ }^{1} \mathrm{H}\right\}$-resonances belonging to amidoxime functions are to be expected, four for each of the two $C_{\mathrm{i}}$ dimers and eight for each enantiomer, indistinguishable from one another in achiral media.

This behaviour can indeed be observed over a chemical shift range of 7 ppm ( $c f$. Fig. 4). The 16 observed signals can easily be ordered into four groups, based on their chemical shifts, line widths and fitted integrals ( $\pm 10 \%$ maximum integration deviation). The four groups correspond to four different chemical environments expected for the simplified case of a single molecule in the $C_{\mathrm{i}}$ point group. Within each group there are two signals of comparable intensity. In the context of the previous rationale, these can be assigned to the $C_{1}$ forms, since eight magnetically different amidoxime groups are to be expected in the enantiomers, which have identity $(E)$ as the only symmetry element. Moreover, each of the two signals of comparable intensity within each of the four groups resembles another signal in terms of chemical shift, that consequently belongs to one of the $C_{\mathrm{i}}$ symmetric forms. This observation can be elegantly explained, as each half of the enantiomers resembles the orientation in one of the $C_{\mathrm{i}}$ isomers. 
Further, this hypothesis is consistent with the chemical shift difference observed in the $C_{\mathrm{s}}$-symmetric ligand 4. In conclusion, the appearance of the amidoxime resonances in the ${ }^{13} \mathrm{C}\left\{{ }^{1} \mathrm{H}\right\}$ spectrum of $\mathbf{1 1}$ is fully consistent with the picture of isomerism as deduced from the X-ray diffraction data. The distribution of these isomers is not fully probabilistic, as in this case all 16 signals would be of equal intensity due to equal population of the four forms.

\section{Structural analysis (part 2)}

In the structure of 11 (Fig. 3), the apical pyrimidine donor N4 occupies the position trans to the $\mu$-oximato oxygen atom. The cation charge is compensated by four trifluoroacetate counterions which form intermolecular hydrogen bonds to the cation's hydroxyl and amino functions. The monomeric motif is self-complementary; in the dimer, the metal ions are coordinatively saturated in reciprocal fashion by deprotonated hydroxyl groups of the other half of the molecule.

Most notably, the structure of $\mathbf{1 1}$ is reminiscent of cryptate complexes, with the two cobalt(III) ions completely shielded from their surroundings as a consequence of dimerization. The geometry which results from dimerization is best described in terms of a least-squares planes analysis. In the asymmetric octahedral motif, three best planes can be defined by the coordinates of $\mathrm{N} 2$, N5, N6, N7 (plane 1), N2, O3', N6, N4 (plane 2) and O3', N5, N4, N7 (plane 3) (cf. Fig. 5). The cobalt ion surrounded by these atoms deviates from the planes by $0.0683(11) \AA$, $0.0578(12) \AA$ and $0.0184(11) \AA$, respectively, while the interplanar angles are $86.63(06)^{\circ}$ (planes $1 / 2$ ), 88.41(06) ${ }^{\circ}$ (planes $2 / 3$ ), and $89.85(06)^{\circ}$ (planes $3 / 1$ ). This characterizes a slightly distorted octahedral coordination environment around cobalt. The symmetry-related second cobalt ion (by inversion) is displaced from the planes by $2.7209(24) \AA, 0.8478(30) \AA$ and $2.6908(21) \AA$, respectively, which defines a "slipped cofacial dimer". This term was coined previously $^{32}$ and indicates that there are pairs of parallel faces in two octahedra (in the present case due to inversion symmetry) while the centres of the octahedra are displaced ("slipped") with respect to one another.

Two other planes can be defined by the atomic coordinates of $\mathrm{N} 2, \mathrm{Co} 1, \mathrm{O}^{\prime}$ and $\mathrm{N} 2, \mathrm{O} 3, \mathrm{O}^{\prime}, \mathrm{N} 2$ ' to further characterize the outof-plane displacement of the bis- $\mu$-oximato bridge (see Fig. 5). The angle defined by these planes is $43.21(10)^{\circ}$. The bridging motif
Table 2 Selected interatomic distances $(\AA)$ and angles $\left({ }^{\circ}\right)$ for $\mathbf{1 1} \cdot 12 \mathrm{H}_{2} \mathrm{O}$

\begin{tabular}{|c|c|c|c|}
\hline $\mathrm{Co} 1 \cdots \mathrm{Col}^{\prime}$ & $3.812(1)$ & $\begin{array}{l}\mathrm{N} 2-\mathrm{O} 3-\mathrm{Col}^{\prime a} \\
\mathrm{Co} 1-\mathrm{N} 2-\mathrm{O} 3\end{array}$ & $\begin{array}{l}119.33(14) \\
122.14(15)\end{array}$ \\
\hline $\mathrm{Co} 1-\mathrm{N} 2$ & $1.907(2)$ & $\mathrm{O} 3^{\prime}-\mathrm{Co} 1-\mathrm{N} 2$ & $90.93(8)$ \\
\hline $\mathrm{N} 2-\mathrm{O} 3$ & $1.385(3)$ & Col-N2-O3-Col' & $67.9(2)$ \\
\hline $\mathrm{O} 3^{\prime}-\mathrm{Co} 1$ & $1.919(2)$ & N4-Co1-O3' & 173.73(9) \\
\hline Co1-N4 & $1.909(2)$ & $\mathrm{N} 4-\mathrm{Co} 1-\mathrm{N} 2$ & $89.39(9)$ \\
\hline Co1-N6 & $1.911(2)$ & N4-Co1-N6 & 88.61(9) \\
\hline Co1-N5 & $1.919(2)$ & N4-Co1-N5 & $86.71(9)$ \\
\hline Col-N7 & $1.913(2)$ & $\mathrm{N} 4-\mathrm{Co} 1-\mathrm{N} 7$ & $87.11(9)$ \\
\hline $\mathrm{O} 8 \cdots \mathrm{O} 3$ & $2.726(3)$ & N5-Co1-N2-O3 & $45.7(2)$ \\
\hline $\mathrm{O} 10 \cdots \mathrm{O} 11$ & $2.587(4)$ & $\mathrm{O} 3-\mathrm{H} 8-\mathrm{O} 8$ & $162(4)$ \\
\hline $\mathrm{O} 3^{\prime} \cdots \mathrm{O} 10$ & $2.848(2)$ & $\mathrm{O} 11-\mathrm{H} 10-\mathrm{O} 10$ & $169(4)$ \\
\hline \multicolumn{4}{|c|}{ Intermolecular distances: } \\
\hline $\mathrm{O} 11 \cdots \mathrm{O} 31$ & $2.490(1)$ & $\mathrm{N} 13 \cdots \mathrm{O} 400$ & $2.915(1)$ \\
\hline $\mathrm{N} 14 \cdots \mathrm{O} 32$ & $2.902(1)$ & $\mathrm{O} 400 \cdots \mathrm{O} 500$ & $2.840(1)$ \\
\hline $\mathrm{N} 14 \cdots \mathrm{O} 800$ & $2.928(1)$ & 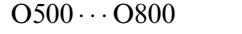 & $2.717(2)$ \\
\hline
\end{tabular}

${ }^{a}$ The angle N2-O3-Co1' defines the parameter $\alpha$, which has been used to characterize bis- $\mu$-oximato bridging (see text). ${ }^{33}$ Primed symbols refer to equivalent positions $1-x, 1-y, 1-z$.

can be clearly distinguished from the type of out-of-plane bis$\mu$-oximato bridging found in copper glyoxime compounds where the relation is approximately rectangular..$^{33}$ Additional interatomic distances and angles are given in Table 2.

\section{Intramolecular H-bonding in the solid state}

The hydrogen bonds in $\mathbf{1 1}$ are longer than in nickel dimethylglyoxime $\left(\mathrm{O} \cdots \mathrm{O}: 2.45 \AA^{34}\right)$ and not equivalent. However, there is no doubt that hydrogen bonding is present as the $\mathrm{O} \cdots \mathrm{O}$ interatomic distances are significantly smaller than the sum of the van der Waals radii $\left(2 \times 1.52 \AA^{35}\right.$ vs. 2.73 and $2.59 \AA$, respectively; see Table 2). Geometric variations of hydrogen bonding parameters can arise due to secondary interactions with water of crystallization, ${ }^{36}$ but in the present case the hydrogen bonding pattern formed by the oxime functions is rather characteristic of a bis- $\mu$-oximato bridged dimer. The hydrogen bond formed between the bridging oxygen atom and the adjacent hydroxyl group has a larger interatomic distance ("central" O3 $\cdots$ O 8) than the hydrogen bond formed between the non-coordinating

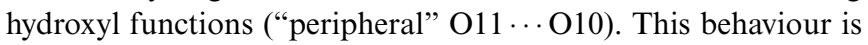
also observed in copper dimethylglyoxime ${ }^{37}$ and can be explained by a decreased hydrogen bond donor capability of the coordinated oxygen atom $\left(\mathrm{O3}^{\prime}\right)$. Further, as there is a short contact between
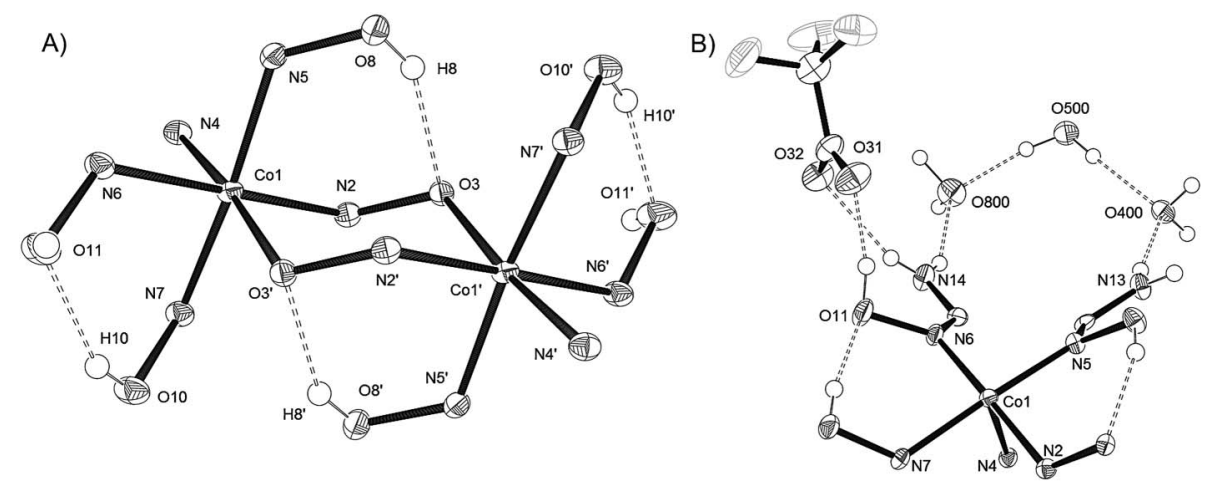

Fig. 5 Simplified representation of the coordination octahedra and $\mathrm{H}$-bonding in $\left.\left[\mathrm{Co}^{\mathrm{III}}{ }_{2}(4-\mathrm{H})_{2}\right]\left(\mathrm{OCOCF}_{3}\right)_{4} \cdot 12 \mathrm{H}_{2} \mathrm{O}\right]$ (outer coordination sphere omitted for clarity). A) Intramolecular H-bonding pattern in the dimer. B) Intermolecular H-bonding pattern in the asymmetric unit (this motif, when doubled, produces the structure of the whole molecule). 


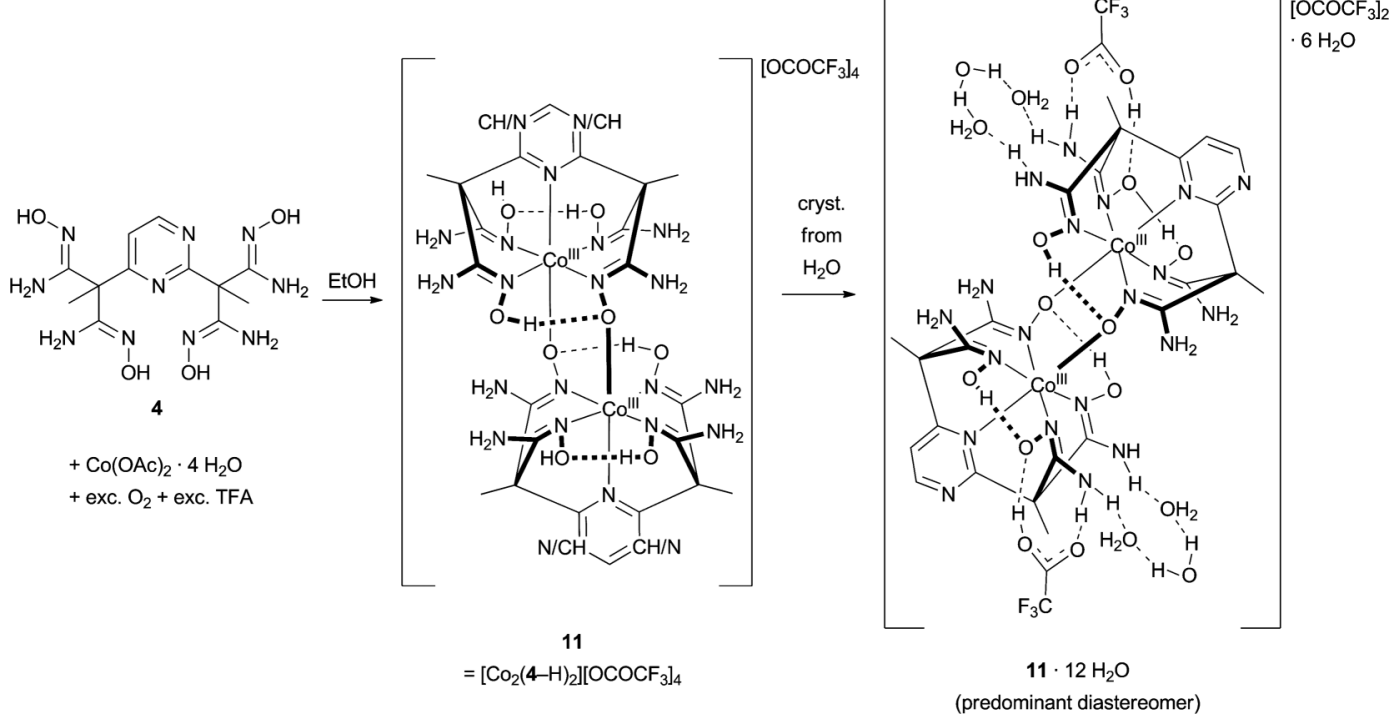

Fig. 6 Schematic representation of cation structures and hydrogen bond motifs in $11 \cdot 12 \mathrm{H}_{2} \mathrm{O}$.

$\mathrm{O}^{\prime}$ and $\mathrm{O} 10$ ( $c f$. Table 2 and Fig. 5), the presence of bifurcated $\mathrm{H}-$ bonds involving the hydroxyl group $\mathrm{O} 10-\mathrm{H} 10$ and oxygen atoms O11/O3' (and symmetry equivalents) cannot be ruled out. Such hydrogen bonding may provide an additional link between the two halves of the molecule.

\section{Intermolecular H-bonding in the solid state}

The presence of amidoxime functions makes intermolecular hydrogen bonding in $\mathbf{1 1} \cdot 12 \mathrm{H}_{2} \mathrm{O}$ diverse. Two of the four trifluoroacetate anions per formula unit form strong hydrogen bonds to the hydroxyl functions serving as acceptors for the peripheral macrocyclic intramolecular hydrogen bonds (cf. Fig. 5 B, Fig. 6). The short contact indicates that trifluoroacetate may, alternatively, be interpreted as trifluoroacetic acid (TFA) acting as a hydrogen bond donor (instead of trifluoroacetate acting as an acceptor). Based on this argument, the compound can be reformulated as a trifluoroacetic acid adduct of the composition $\left\{\left[\mathrm{Co}^{\mathrm{III}}(4-\right.\right.$ $\left.2 \mathrm{H})]_{2}\left[\mathrm{OCOCF}_{3}\right]_{2} \cdot 2 \mathrm{TFA}\right\}$. This explains why the dication $\left[\mathrm{Co}^{\mathrm{III}}(4\right.$ $-2 \mathrm{H})]_{2}{ }^{2+}$ is observed in ESI mass spectra as the dominant signal, whereas a tetracation is not observed (see Experimental section). The other two trifluoroacetate anions form weak hydrogen bonds to an amino function (not shown in Fig. 5). Six of the twelve water molecules of crystallization form two 'hydrogen bond arches', related by inversion symmetry, which connect the amino functions of the methylmalonamidoxime residue that does not contain the bridging $\mu$-oximato function ( $c f$. Fig. $5 \mathrm{~A} / \mathrm{B}$, Table 2). The residual six water molecules form hydrogen bonds with the weakly bound trifluoroacetate ions. There are no hydrogen bonds involving the non-coordinating nitrogen atoms of the pyrimidine ring.

\section{Conclusions}

Compound 4 binds to cobalt(III) ions in tetrapodal pentadentate fashion, with formation of a dinuclear complex containing a sixmembered out-of-plane bis- $\mu$-amidoximato metallacycle and a macrobicyclic structure based on hydrogen bonds. This unexpected dimerization results in efficient shielding of the central metal ions. The influence of coordination isomerism, which derives from the use of a pyrimidine core (as opposed to an azine of higher symmetry ${ }^{38}$ ), on the overall geometry of the complex cation is subtle. The presence of trifluoroacetic acid during complexation does not impede the single deprotonation of the capping ligand. Overall, dimerization produces a formal tetracation $\left[\mathrm{CO}_{2}(4-\mathrm{H})_{2}\right]^{4+}$, with both strong and weak hydrogen bonds to its trifluoroacetate counterions in the solid state. In ESI mass spectra, the predominant ion is the dication $\left[\mathrm{Co}_{2}(4-\right.$ $\left.2 \mathrm{H})_{2}\right]^{2+}$ which is a result of further deprotonation of the ligand. Mononuclear ions are observed but their intensity is negligible ( $c f$. Experimental section). We compare the structure of the dimer to that of copper glyoxime dimers, as there appear to be no literature examples of related bis- $\mu$-oximato-bridged cobalt complexes of dioximes. An explanation for their absence might be that, in cobaloximes, significant out-of-plane placement of the hydroxyl functions is regularly accompanied by dislocation of the metal ion in the opposite direction. ${ }^{39}$ Yet, since malonamidoxime itself, which can be viewed as the parent compound of the present ligand, shows out-of-plane location of the hydroxyl function in combination with in-plane location of the metal ion in certain metal complexes, ${ }^{11}$ it can be assumed that this particular motif is prone to form in cobalt(III) compounds of 1,3-dioxime ligands.

In summary, amidoxime ligands of this kind indeed combine certain properties of tetrapodal pentadentate ligands and macrocyclic oxime ligands. However, while amidoxime functions are known to act as versatile bridging donors, ${ }^{40}$ the encapsulation of the metal ions upon dimerization in $\mathbf{1 1}$ is an example of synergism. In effect, compound $\mathbf{4}$ can be considered an "open prison ligand" 4 or a "pseudo-cryptand", as the shielding depends on the selfcomplementarity of the mononuclear ion-ligand fragment rather than on the ligand alone.

Future studies will focus on the exploration of other transition metal complexes of tetrapodal amidoxime ligands, their reactivity, and ligand variations in order to prevent dimerization/coordination isomerism as observed in the present case. The potential of such complexes in electrocatalytic water splitting will be studied. ${ }^{42,43}$ 


\section{Acknowledgements}

Support by the Deutsche Forschungsgemeinschaft (GR 1247/71) is gratefully acknowledged. Thomas Hamfler and Manfred Detlaff are thanked for technical assistance, and Dr Josef Seiffert, Dr Gerald Hörner, Dr Maria Schlangen and Professor Aris Chatzidimitriou-Dreismann are thanked for helpful discussions.

\section{References}

1 D. J. Wesylenko, C. Ganesamoorthy, J. Borau-Garcia and C. P. Berlinguette, Chem. Commun., 2011, 47, 4249-4251.

2 (a) A. Fihri, V. Artero, M. Razavet, C. Baffert, W. Leibl and M. Fontecave, Angew. Chem., 2008, 120(3), 574-577, (Angew. Chem., Int. Ed., 2008, 47, 564); (b) P.-A. Jacques, V. Artero, J. Pécaut and M. Fontecave, Proc. Natl. Acad. Sci. U. S. A., 2009, 106(49), 20627-20632.

3 H. M. Colquhoun, J. F. Stoddart and D. J. Williams, Angew. Chem., 1986, 98(6), 483-503, (Angew. Chem., Int. Ed. Engl., 1986, 25, 487).

4 R. L. Shook and A. S. Borovik, Inorg. Chem., 2010, 49(8), 3646-3660. 5 D. Natale and J. C. Mareque-Rivas, Chem. Commun., 2008, 425-437.

6 L. Caron, H. Bricout, S. Tilloy, A. Ponchel, D. Landy, S. Fourmentin and E. Monflier, Adv. Synth. Catal., 2004, 346(12), 1449-1456.

7 (a) C. Squires, C. W. Baxter, J. Campbell, L. F. Lindoy, H. McNab, A. Parkin, S. Parsons, P. A. Tasker, G. Wei and D. J. White, Dalton Trans., 2006, 2026-2034; (b) R. S. Forgan, B. D. Roach, P. A. Wood, F. J. White, J. Campbell, D. K. Henderson, E. Kamenetzky, F. E. McAllister, S. Parsons, E. Pidcock, P. Richardson, R. M. Swart and P. A. Tasker, Inorg. Chem., 2011, 50(10), 4515-4522.

8 A. Grohmann, Dalton Trans., 2010, 39, 1432-1440.

9 (a) J. Rétey, Helv. Chim. Acta, 1971, 54(8), 2747-2752; (b) M. W. Bartlett and J. D. Dunitz, Helv. Chim. Acta, 1971, 54(8), 2753-2756; (c) W. Pannhorst, Acta Crystallogr., Sect. B: Struct. Crystallogr. Cryst. Chem., 1977, 33, 2384-2388.

10 I. Ruff and K. Burger, Acta Chim. Acad. Sci. Hung., 1966, 47, 143-155.

11 H. Endres and N. Kadkodai-Elyaderani, Z. Naturforsch., 1982, 37b, $1255-1265$.

12 H. Schmidtmann, Ber. Dtsch. Chem. Ges., 1896, 29(2), 1168-1175.

13 F. Eloy and R. Lenaers, Chem. Rev., 1962, 62(2), 155-183.

14 (a) D. A. de Bie, A. Ostrowicz, G. Geurtsen and H. C. van der Plas, Tetrahedron, 1988, 44(10), 2977-2983; (b) A. E. Frissen, A. T. M Marcelis, G. Geurtsen, D. A. de Bie and H. C. van der Plas, Tetrahedron, 1989, 45(16), 5151-5162.

15 S. Takano, Y. Yano and W. Tagaki, Chem. Lett., 1981, 1177.

16 C. Zimmermann, F. W. Heinemann and A. Grohmann, Eur. J. Inorg. Chem., 2001, (2), 547-555.

17 (a) A. Gerli, M. Sabat and L. G. Marzilli, J. Am. Chem. Soc., 1992, 114, 6711-6718; (b) S. Kiani, R. J. Staples and A. B. Packard, Acta Crystallogr., Sect. C: Cryst. Struct. Commun., 2002, 58, m593-m595.

18 A. Thibon, J. England, M. Martinho, V. G. Young, J. R. Frisch, R. Guillot, J. J. Girerd, E. Münck, L. Que and F. Banse, Angew. Chem., 2008, 120(37), 7172-7175, (Angew. Chem., Int. Ed., 2008, 47, 7064).

19 (a) M. Achmatowicz, L. S. Hegedus and S. David, J. Org. Chem., 2003, 68(20), 7661-7666; (b) A. L. Reiff, E. M. Garcia-Frutos, J. M. Gil, O. P. Anderson and L. Hegedus, Inorg. Chem., 2005, 44(25), 9162-9174.

20 (a) M. Grenness and K. B. Oldham, Anal. Chem., 1972, 44(7), 11211129; (b) A. M. Bond, K. B. Oldham and G. A. Snook, Anal. Chem., 2000, 72(15), 3492-3496.
21 Oxford Diffraction, CrysAlis CCD and CrysAlisPro, Version 1.171.33.66, Abingdon, Oxford, UK, Oxford Diffraction Ltd, 2008.

22 M. C. Burla, R. Caliandro, M. Camalli, B. Carrozzini, G. L. Cascarano, L. De Caro, C. Giacovazzo, G. Polidori and R. Spagna,, J. Appl. Crystallogr., 2005, 38, 381-388.

23 G. M. Sheldrick, SHELXL-97, Program for refinement of crystal structures, University of Göttingen, Germany, 1997.

24 L. J. Farrugia, J. Appl. Crystallogr., 1997, 30, 565.

25 L. Wang and H. Zipse, Liebigs Ann., 1996, (10), 1501-1509.

26 T. Matsumoto, D. Yoshida and H. Tomita, Agric. Biol. Chem., 1981, 45(9), 2031-2035.

27 (a) F. T. Oakes and N. J. Leonard, J. Org. Chem., 1985, 50, 49864989; (b) J. Pakusch, H.-D. Beckhaus and C. Rüchardt, Chem. Ber., 1991, 124, 1191-1198; (c) E. Diez-Barra, A. de la Hoz, A. Moreno and P. Sanchez-Verdu, J. Chem. Soc., Perkin Trans. 1, 1991, 25892592.

28 (a) G. E. Hilbert and T. B. Johnson, J. Am. Chem. Soc., 1930, 52(3), 1152-1157; (b) N. Whittaker and T. S. G. Jones, J. Chem. Soc., 1951, $1565-1570$.

29 W. S. Matthews, J. E. Bares, J. E. Bartmess, F. G. Bordwell, F. J. Cornforth, G. E. Drucker, Z. Margolin, R. J. McCallum, G. J. McCollum and N. R. Vanier, J. Am. Chem. Soc., 1975, 97(24), 70067014.

30 (a) T. Bug and H. Mayr, J. Am. Chem. Soc., 2003, 125, 12980-12986; (b) H. Mayr and A. R. Ofial, J. Phys. Org. Chem., 2008, 21, 584 595.

31 T. Ohkuma, S. Hashiguchi and R. Noyori, J. Org. Chem., 1994, 59(1), 217-221.

32 (a) Y. Kobuke and H. Miyaji, J. Am. Chem. Soc., 1994, 116, 4111-4112; (b) S. Morikawa, C. Ikeda, K. Ogawa and Y. Kobuke, Lett. Org. Chem., 2004, 1, 6-11; (c) H. Nakagawa, K. Ogawa, A. Satake and Y. Kobuke, Chem. Commun., 2006, 1560-1562.

33 (a) B. Cervera, R. Ruiz, F. Lloret, M. Julve, J. Cano, J. Faus, C. Bois and J. Mrozinski, J. Chem. Soc., Dalton Trans., 1997, (3), 395-401; (b) R. Ruiz, F. Lloret, M. Julve, J. Faus, M. C. Muñoz and X. Solans, Inorg. Chim. Acta, 1998, 268, 263-269.

34 D.-X. Li, D.-J. Xu and Y.-Z. Xu, Acta Crystallogr., Sect. E: Struct. Rep. Online, 2003, 59, m1094-1095.

35 (a) A. Bondi, J. Phys. Chem., 1964, 68(3), 441-451; (b) S. S. Batsanov, Inorg. Mater., 2001, 37(9), 871-885.

36 (a) J. M. Rubin-Preminger and U. Englert, Acta Crystallogr., Sect. E: Struct. Rep. Online, 2006, 62, m2659-m2660; (b) J. M. Rubin-Preminger and U. Englert, Acta Crystallogr., Sect. E: Struct. Rep. Online, 2006, 62, $\mathrm{m} 2972-\mathrm{m} 2973$.

37 (a) E. Frasson, R. Bardi and S. Bezzi, Acta Crystallogr., 1959, 12, 201205; (b) R. E. Rundle and C. V. Banks, J. Phys. Chem., 1963, 67(2), 508-509.

38 P. J. Steel, Acc. Chem. Res., 2005, 38, 243-250.

39 D. J. A. De Ridder, E. Zangrando and H.-B. Bürgi, J. Mol. Struct., 1996, 374, 63-83.

40 S.-G. Roh, A. Proust, F. Robert and P. Gouzerh,, J. Cluster Sci., 1996, 7(4), 593-627.

41 G. A. Lawrance and P. G. Lye, Comments Inorg. Chem., 1994, 15(5-6), 339-368.

42 P. Du, K. Knowles and R. Eisenberg, J. Am. Chem. Soc., 2008, 130(38), 12576-12577.

43 P.-A. Jacques, V. Artero, J. Pécaut and M. Fontecave, Proc. Natl. Acad. Sci. U. S. A., 2009, 106(49), 20627-20632. 